\title{
A Comparative Study of Temperature Optimal Control in a Solid State Fermentation Process for Edible Mushroom Growing
}

\author{
K. J. Gurubel, ${ }^{a, *}$ A. Sanchez, ${ }^{\text {b }}$ A. Coronado-Mendoza, ${ }^{a}$ \\ and E. N. Sanchez \\ aDepartamento de Ingenierías, Universidad de Guadalajara, \\ CUTONALA, Tonalá, Jalisco, México, Avenida Nuevo Periférico \\ No. 555, Ejido San José Tatepozco, C.P. 45425 \\ ${ }^{b}$ Departamento de Control Automático, CINVESTAV del IPN, \\ Unidad Guadalajara, Zapopan, Jalisco, México \\ Av. Del Bosque 1145, Col. El Bajío, CP. 45019
}

doi: $10.15255 / C A B E Q .2016 .957$

Original scientific paper

Received: July 27, 2016

Accepted: March 11, 2017

In this paper, optimal control strategies for temperature trajectory determination in order to maximize thermophilic bacteria in a fed-batch solid-state fermentation reactor are proposed. This process is modeled by nonlinear differential equations, which has been previously validated experimentally with scale reactor temperature profiles. The dynamic input aeration rate of the reactor is determined to increase microorganisms growth of a selective substrate for edible mushroom cultivation. In industrial practice, the process is comprised of three thermal stages with constant input air flow and three types of microorganisms in a 150-hour lapse. Scytalidium thermophilum and actinobacteria are desired in order to obtain a final biomass composition with acceptable microorganisms concentration. The Steepest Descent gradient algorithm in continuous time and the Gradient Projection algorithm in discrete-time are used for the process optimal control. A comparison of simulation results in the presence of disturbances is presented, where the resulting temperature trajectories exhibit similar tendencies as industrial data.

Key words:

aerobic solid substrate fermentation, optimal temperature trajectory, steepest descent gradient, gradient projection, selective substrate

\section{Introduction}

The solid-state fermentation (SSF) is a process in which microorganisms grow on solid materials or inside solid porous particles in the absence of free water; the final result is a nutritionally enriched product, with a higher content of proteins and vitamins than the original substrate ${ }^{1}$. In recent decades, there has been a growing interest in SSF technology to obtain a wide variety of products, such as enzymes, pigments, aromatic compounds, flavoring, hormones, acids, alcohols, proteins, antibiotics, spores, among others. ${ }^{2,3}$ There are research results on new applications of SSF for the control of the environment, treatment and biodegradation of hazardous or undesirable compounds, and detoxification of agro-industrial waste. ${ }^{4,5} \mathrm{An}$ interesting industrial application of SSF, known as "Phase 2", is the preparation of a selective substrate employed in $A$. bisporus mushroom cultivation. ${ }^{6,7}$ Edible mushrooms are widely cultivated for use in gastronomy.

"Corresponding author: joel.gurubel@cutonala.udg.mx
In the SSF industrial process (phase 2), the row substrate is packaged in a convection forced batch bioreactor without overturning. Cultivation takes a 150-hour lapse and is divided into 3 isothermal stages: preconditioning $\left(40^{\circ} \mathrm{C}, 40 \mathrm{~h}\right)$, pasteurization $\left(55^{\circ} \mathrm{C}, 10 \mathrm{~h}\right)$ and conditioning $\left(40{ }^{\circ} \mathrm{C}, 40 \mathrm{~h}\right) .{ }^{8}$ Air is supplied in a homogenous manner for controlling the reactor temperature and humidity; the air is fed to the volume of the reaction by manipulating freshair flow and/or the recirculation ratio guaranteeing aerobic conditions. The air and temperature conditions are experimentally determined and validated in industry, based on restricted knowledge of the SSF phenomena. The objective is to produce microbial populations, which encourages growth of the $A$. bisporus during the cultivation stage, such as the Scytalidium thermophilum and some Actinobacteria whilst eliminating competitors and inhibitors. ${ }^{9}$ However, the mentioned temperature profiles do not necessarily guarantee that the selective substrate will have an acceptable yield, due to the complexity of the SSF phenomena, such as mass and energy transfer, biological behavior, and operating condi- 
tions. In the literature, several models for forced aeration SSF bioreactor using a distributed parameter model or lumped-parameter model to reproduce its main operating features have been proposed. ${ }^{10-13}$ These mathematical models are designed for control strategy application, state estimation, and parameter optimization for many different operating conditions investigated via simulations. These approaches provide a good technical and economic starting point for large-scale experimental work. The major challenge in the SSF process scale-up is the heat removal from the bed of solids with inter-particle air. ${ }^{11,12}$ For large-scale SSF bioreactor design, evaporation is one of the most effective heat removal mechanisms. However, continued evaporation can dry the bed out to water activities enough to restrict growth rates and product formation. ${ }^{12}$ Therefore, the maintenance of the water activity of the bed becomes a consideration, which guides design and operation. In SSF reactors, the air phase plays a central role in heat removal and in the oxygen supply to the surface of the particles. Therefore, the general scale-up problem focuses on heat removal as the key scale-up criterion and maintenance of water activity. ${ }^{13,14}$ In Chen et al. ${ }^{14}$ an experimental SSF system for cellulase production through periodical control of air pressure pulsation and internal air circulation is proposed. Although, it enhances the heat transfer and reduces temperature gradients in the process, this technique is operated in open loop and recalculations are required at different operating conditions. An optimal control algorithm for optimal temperature trajectory determination to maximize thermophilic fungi and actinobacteria production in a SSF reactor is proposed in Gonzalez-Figueredo et al. ${ }^{15}$ Performance of the control algorithm for a 250-hour process lapse via simulation is presented. Temperature profiles calculation are similar to experimental ones and an increase in the thermophilic fungi and actinobacteria concentration is obtained. However, transient state during the first 60 hours is observed and disturbances are not considered in the process. In Sanchez et al. ${ }^{16}$ a continuous second-order sliding mode controller to track temperature profiles in a FSS dynamic model describing the behavior of relevant system states is proposed. The goal is to obtain a maximum $S$. thermophilum concentration, which guarantees better mushroom yields in shorter operating times. The performance of the closedloop scheme is presented via simulations. The results show a good approximation of the experimental temperature profiles observed in a pilot-plant reactor, but the convergence time is large and an increase in control action (aeration rate), which represent energy excess consumption, is displayed. This paper describes: a) a reduced-scale SSF lumped-parameter model with forced convection to selective substrate production for edible $A$. bisporus mushroom cultivation, b) optimal control strategy application to optimize phase 2 of the SSF industrial process. The non-linear model is represented by ordinary differential equations, which considers estequiometric and chemical kinetics of the microbial reaction for three categories of microorganisms. The model also considers heat transfer, mass transfer with microbial reaction, oxygen concentration and internal temperature.

\section{Materials and methods}

\section{SSF lumped-parameter model}

The model is based on a first-principle lumped-parameter mathematical model that estimates the non-isothermal dynamical behavior of a pilot-plant SSF reactor employed for phase II composting of substrate for the A. bisporus cultivation under controlled conditions. The experimental reactor has a rectangular shape with dimensions of $0.8 \times$ $0.6 \times 0.5 \mathrm{~m}, 80 \mathrm{~kg}$ substrate capacity and isolated by a $5 \mathrm{~cm}$ glass fiber jacket. The substrate composed of organic material residues (wheat straw, soy flour, and poultry manure) is packed into the reactor and remains static without tipping. Fresh air is fed through a manifold, with evenly distributed diffusers inside the reactor, to maintain homogeneous conditions of temperature and oxygen concentration. Input air flow is controlled by a valve placed before the manifold. Rotameters measure the input air flow after the valve and at the inlet point of each diffuser. Output gases flow through a duct placed at the upper lid of the reactor. Bulk temperature is continuously measured at 10 points within the bed using pt-100 RTDs. Excess water is drained by gravity from the bottom of the reactor. Figure 1 shows a scheme of the SSF experimental reactor.

Microbial growth is obtained from a FSS laboratory scaled reactor under controlled conditions, employed in the preparation of compost for Agaricus bisporus mushroom cultivation. ${ }^{10,15}$ In a previous research, ${ }^{15}$ the following features of the experimental FSS process for phase II composting of substrate for $A$. bisporus cultivation have been established: The heat internal generation facilitates water evaporation. The steam is taken up by air flow. As the air approximates the top of the compost, it comes to be saturated and the loss of latent heat is minimal. Temperature gradients measured in each of the compost zones are not significant. Based on the above features, the following suppositions were adopted to model a fed batch SSF reactor with homogeneous forced aeration: 


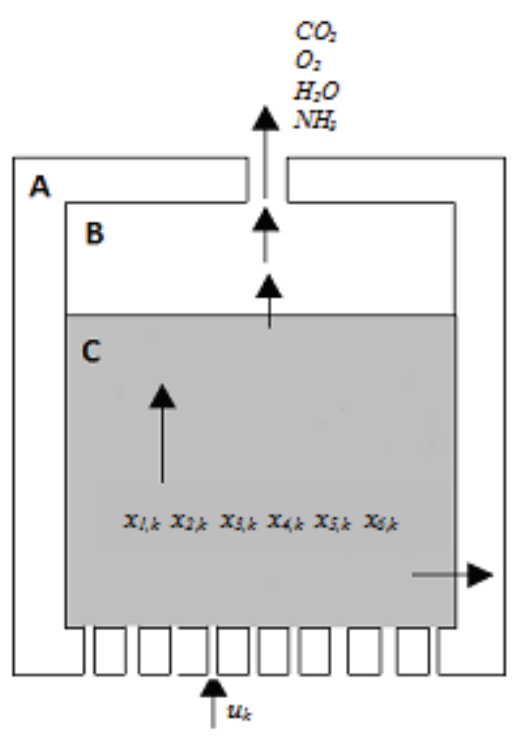

Fig. 1 - Experimental reactor scheme. A: Wall, B: Headspace, $C$ : Substrate, $x_{i}=$ Dynamical states, $u_{k}=$ Input air flow

- Solid, liquid, and gaseous phases coexist in a representative part of the volume, phase changes (evaporation and condensation), and microbial reactions occur in a uniform way throughout the reactor.

- Temporary change in the substrate height is proportional to its weight and follows the Maxwell viscoelastic model. ${ }^{15}$

- Initial concentration for each microorganism considered in the model is the same, and there is no competition among them. Temperature profile presents more influence from the reaction enthalpies. ${ }^{10}$

- Parameters remain constant throughout the culture. Temperature and water activity do not affect kinetic parameters. ${ }^{10}$

- Solid and liquid fractions in the substrate are assumed constant throughout the time.

- Input air humidity is maintained constant.

The developed nonlinear model consists of six ordinary differential equations, which describes the matter transport, microorganisms kinetics and energy balance as follows ${ }^{16}$ :

$\dot{x}_{1}=\left(\mu_{1}-\lambda_{1}\right) x_{1}$

$\dot{x}_{2}=\left(\mu_{2}-\lambda_{2}\right) x_{2}$

$\dot{x}_{3}=\left(\mu_{3}-\lambda_{3}\right) x_{3}$

$\dot{x}_{4}=\sum_{i=1}^{3}\left(-\frac{1}{\gamma_{i}} \mu_{i}+\lambda_{i}\right) x_{i}$

$\dot{x}_{5}=\sum_{i=1}^{3} \phi_{i} \mu_{i} x_{i}+\frac{1}{V}\left(x_{5 s s}-x_{5}\right) u$

$\dot{x}_{6}=\varphi\left(-\psi\left(x_{6}-x_{6 s s}\right)+\sum_{i=1}^{3} \delta_{i} \mu_{i} x_{i}-\zeta\left(\pi\left(x_{6}\right)\left(1-\pi_{f}\left(x_{6}\right)\right) u\right)\right.$ where $x_{1}, x_{2}, x_{3}\left(\mathrm{~kg} \mathrm{~m}^{-3}\right)$ are states which represent Actinobacteria, S. thermophilum, and inhibitor microorganism concentration, respectively; $x_{4}\left(\mathrm{~kg} \mathrm{~m}^{-3}\right)$ is the substrate state, $x_{5}\left(\mathrm{~kg} \mathrm{~m}^{-3}\right)$ is the oxygen state, and $x_{6}\left({ }^{\circ} \mathrm{C}\right)$ is the internal temperature. $\mu$ is the microbial growth specific rate, $\lambda$ is the mortality specific rate, $\gamma_{1}$ represents the substrate production coefficient, $\phi$ is the oxygen consumption coefficient, $V$ is the volume of the reactor $\left(\mathrm{m}^{3}\right), u\left(\mathrm{~m}^{3} \mathrm{~h}^{-1}\right)$ is the input fresh air flow of the reactor, $\varphi$ is a constant relating to the solid and humid content of the substrate, $\psi\left(\mathrm{kJ} \mathrm{m}^{-3} \mathrm{~h}^{-1}{ }^{\circ} \mathrm{C}^{-1}\right)$ is a heat transfer constant to the outside, $\delta\left(\mathrm{kJ} \mathrm{kg}^{-1}\right)$ is the heat generation coefficient, $\zeta$ is the coefficient relating to air density and reactor volume $(\mathrm{kg}), \pi$ and $\pi_{f}\left(\mathrm{~kJ} \mathrm{~kg}^{-1}\right)$ are functions that depend on the saturation enthalpy and damp heat, respectively.

The microbial growth specific rates are described by pseudo-Michaelis-Menten kinetic expression on the substrate and oxygen concentrations. ${ }^{10}$ With this assumption, the microbial growth equation for each microorganism category is stated as follows, $i=1$ : Actinobacteria, $i=2: S$. thermophilum and $i=3$ : Inhibitor microorganisms

$$
\mu_{i}=\mu_{\max , i} x_{6} \frac{x_{4}}{K s_{i}+x_{4}} \frac{x_{5}}{K o_{i}+x_{5}}, \quad i=1,2,3
$$

where $\mu_{\text {max }, i}\left(\mathrm{~h}^{-1}\right)$ is the microbial growth maximum rates depending on the temperature, $K s_{i}\left(\mathrm{~kg} \mathrm{~m}^{-3}\right)$ is the substrate saturation constant, and $K o_{i}\left(\mathrm{~kg} \mathrm{~m}^{-3}\right)$ is the oxygen saturation constant. Death specific rates are described using standard Arrhenius equation ${ }^{10}$

$$
\lambda_{i}=a_{d, i} \exp \left(-b_{d, i}\left(x_{6}+273\right)\right), \quad i=1,2,3
$$

where $a_{d, i}\left(\mathrm{~h}^{-1}\right)$ and $b_{d, i}(\mathrm{~K})$ are constants, and the death equation for each microorganism category is stated as for the microbial growth ones. The parameter values calculation for the dynamic states are found in Sanchez et al. ${ }^{16}$ The operating conditions are shown in Table 1.

Table 1 -Parameter values

\begin{tabular}{c|c|c|c|c|c}
\hline \multicolumn{3}{c|}{ Initial conditions } & \multicolumn{3}{c}{ Cost functional } \\
\hline State & Value & Unit & Parameter & Value & Unit \\
\hline$x_{1, k}$ & 0.1 & $\mathrm{~kg} \mathrm{~m}^{-3}$ & $R$ & 0.1 & - \\
$x_{2, k}$ & 0.1 & $\mathrm{~kg} \mathrm{~m}^{-3}$ & $Q$ & 0.12 & - \\
$x_{3, k}$ & 0.1 & $\mathrm{~kg} \mathrm{~m}^{-3}$ & $\tau$ & 0.5 & $\mathrm{~h}$ \\
$x_{4, k}$ & 40 & $\mathrm{~kg} \mathrm{~m}^{-3}$ & & & \\
$x_{5, k}$ & 0.3 & $\mathrm{~kg} \mathrm{~m}^{-3}$ & & & \\
$x_{6, k}$ & 30 & ${ }^{\circ} \mathrm{C}$ & & & \\
$u_{k}^{(0)}$ & 0.1 & $\mathrm{~m}^{3} \mathrm{~h}^{-1}$ & & \\
\hline \multicolumn{5}{c}{}
\end{tabular}




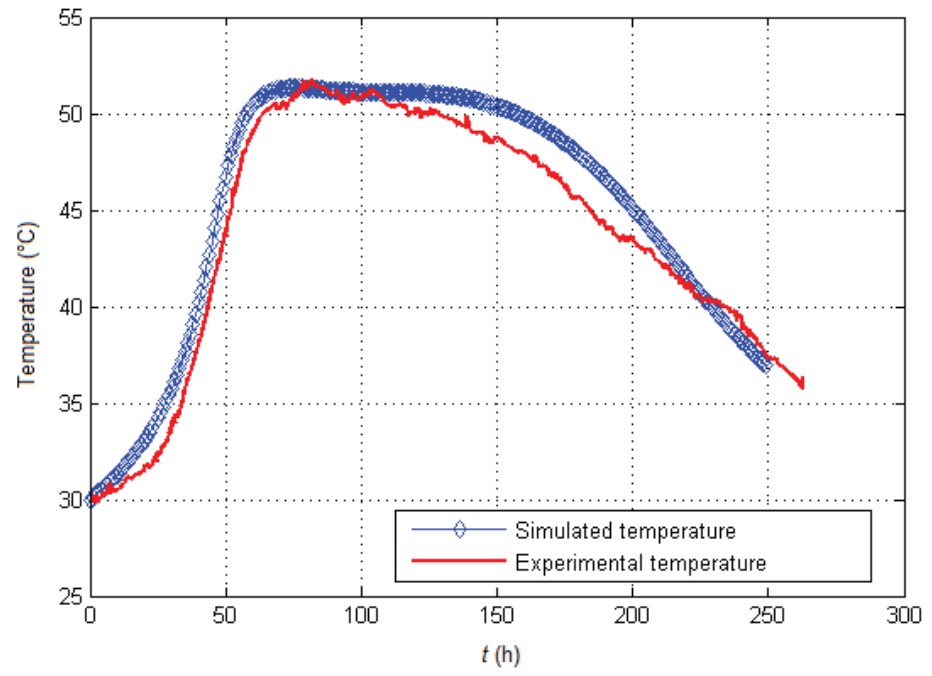

Fig. 2 - Temperature profile comparison

The development of the proposed lumped-parameter FSS mathematical model has been a key issue in the design, scale-up, and control of fermentation technology. ${ }^{10,15,16}$ Different approaches have been applied considering selective substrate, operating conditions, and sensitivity analysis. A sensitivity analysis for stoichiometric, kinetic, and mass transfer parameters is presented in Gonzalez-Figueredo et al. ${ }^{10}$ The performed analysis revealed the kinetic parameters with the largest influence on the model. Some of these parameters are the reaction enthalpies $\delta_{i}$, which, even when adjusted for a better approximation, are considered constant throughout the process and independent of the
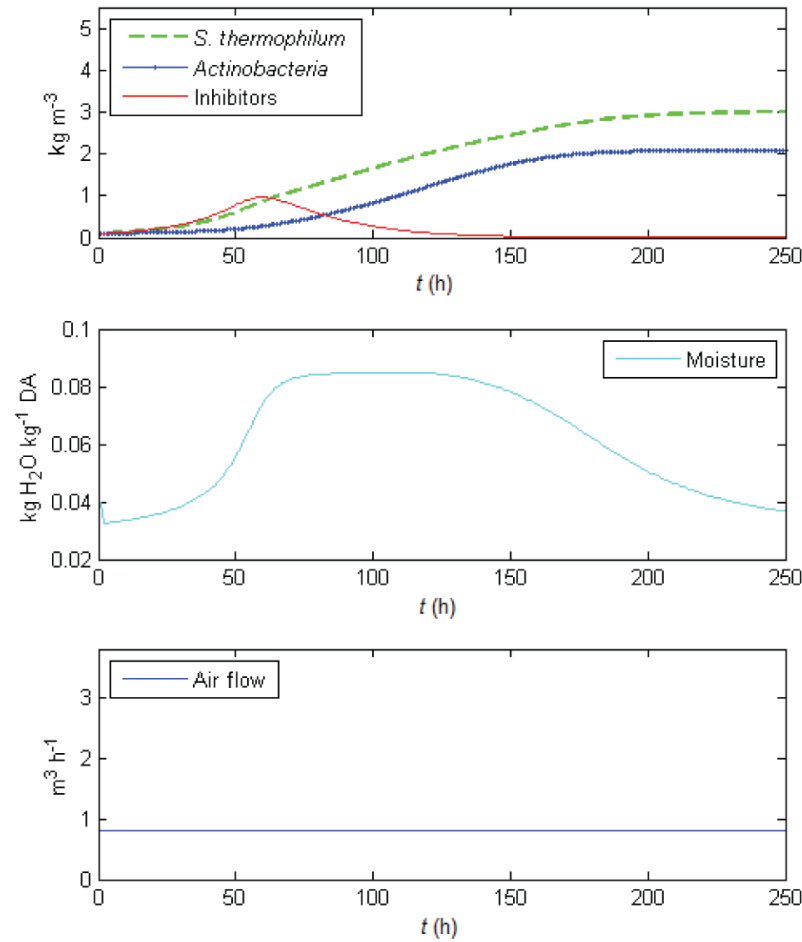

Table 2 -Sensitive parameter

\begin{tabular}{c|c|c|c}
\hline Parameter & Average value & Unit & $\begin{array}{c}\text { Standard } \\
\text { deviation }\end{array}$ \\
\hline$\delta_{i}$ & 26644 & $\mathrm{~kJ} \mathrm{~kg}^{-1}$ & 1723 \\
\hline
\end{tabular}

compost composition and microbial category, affecting considerably the maximum temperature attainable. The proposed model accurately predicts temperature trajectories and the complex microbial dynamics taking place in the SSF reactor. The standard deviation of the kinetic parameter is presented in Table 2.

The temperature profile is obtained with experimental data of the scale reactor monitored throughout the process and is compared with the mathematical model described above. The comparative result is illustrated in Figure 2.

As can be seen in Figure 2, an acceptable agreement between experimental and simulated temperature profiles is exhibited. For this control policy, the "on-set" and "heat-peak" periods are of similar duration with a maximum calculated temperature of $52.7{ }^{\circ} \mathrm{C}$, thus promoting the growing of the thermophilic microorganism. The model presents transient errors in the range of 120 to 200 hours, which may require a better characterization of the process; however, with this result it is possible to guarantee a good approximation of the actual process response. Figure 3 shows the results of the SSF model experimental validation with a constant input air flow equal to $0.8 \mathrm{~m}^{3} \mathrm{~h}^{-1}$.
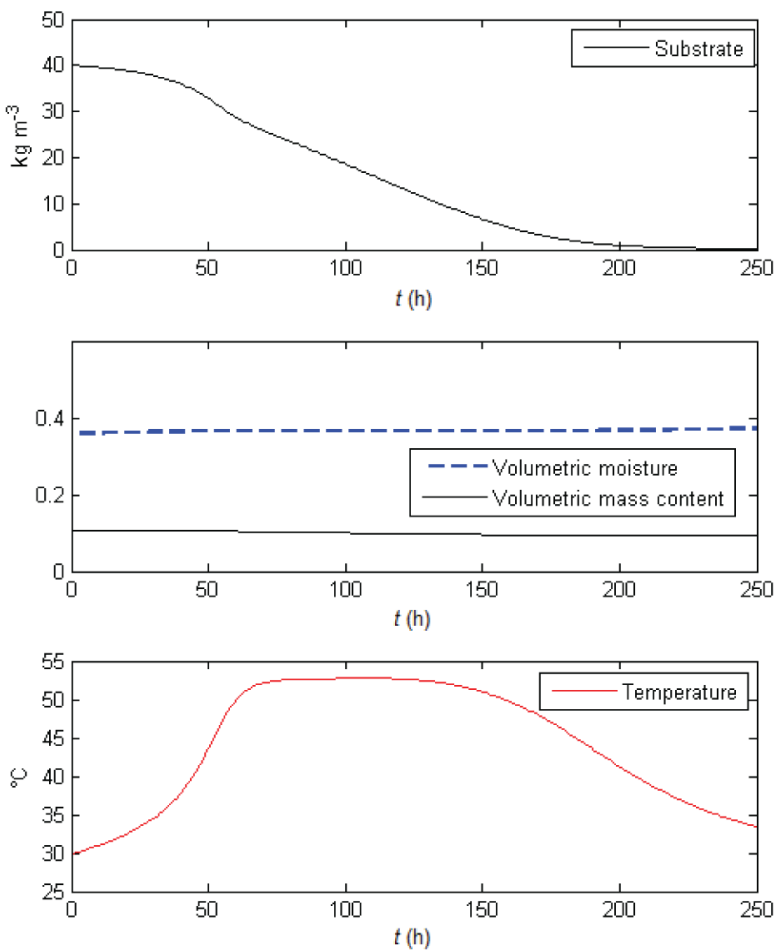

Fig. 3 - SSF Model validation with constant airflow rate 
The calculated final concentrations of $S$. thermophilum $\left(x_{2}\right)$ and Actinobateria $\left(x_{1}\right)$ are $3.01 \mathrm{~kg} \mathrm{~m}^{-3}$ and $2.09 \mathrm{~kg} \mathrm{~m}^{-3}$ respectively. Its ratio is within the expected range ${ }^{17}$ giving a positive indication of a good prediction of concentration values. Substrate is exhausted after 250 hours. The objective of this work is to maximize the $S$. thermophilum microorganisms concentration calculating optimal temperature trajectory.

\section{Steepest Descent Gradient algorithm}

In order to apply the steepest descendent optimization algorithm let us consider the nonlinear system:

$$
\dot{x}_{t, i}=f\left(x_{t}, u_{t}\right)
$$

For this system, the following cost functional is defined

$$
J=h\left(x_{t_{f}}\right)+\int_{t_{0}}^{t_{f}} g\left(x_{t}, u_{t}\right) \mathrm{d} t
$$

Then, the associated Hamiltonian is determined as follows

$$
H_{m}=g\left(x_{t}, u_{t}\right)+\sum_{i=1}^{n} p_{i} x_{t, i}
$$

and the respective costates as the Hamiltonian derivative

$$
\dot{p}_{t, i}=-\frac{\partial H_{m}}{\partial x_{t, i}}\left(x_{t}, u_{t}, p_{t}\right)
$$

In order to guarantee the optimal values, the following conditions should be satisfied:

$$
\frac{\partial H_{m}}{\partial u_{t}}\left(x_{t}, u_{t}, p_{t}\right)=0 \quad t \in\left[t_{0}, t_{f}\right]
$$

The algorithm is described in Figure 4, which is initialized by proposing a constant control signal $u^{(0)}$ along the horizon of evaluation. Subsequently, the state equations are solved and the results are stored. Then, the costates are calculated and the Hamiltonian derivative is solved and matched to a pre-selected positive small constant. If the stopping criterion is met, the optimization procedure ends, and if it is not satisfied, a new given control vector function is generated by

$$
u_{t_{k}}^{i+1}=u_{t_{k}}^{i}-\tau \frac{\partial H_{m}^{i}}{\partial u_{t_{k}}} \quad k=0, \ldots . . N-1
$$

where $u_{t_{k}}^{i+1}$ is the new control signal to calculate the states and costates of the system. $\tau$ is a weighting parameter calculated by the secant method.

Theorem 1. If $J$ is convex in $(u, x)$ where $p_{t}<0$ and $a\left(x_{t}, u_{t}\right)$ is convex in $(u, x)$ (or $p_{t}>0$ and $a\left(x_{t}, u_{t}\right)$ is concave in $\left.(u, x)\right)$, then $H_{m}$, is convex (concave) in $(u, x)$ which ensures optimality of the solution $\left(x_{t}^{*}, u_{t}^{*}, p_{t}^{*}\right) \cdot{ }^{18}$

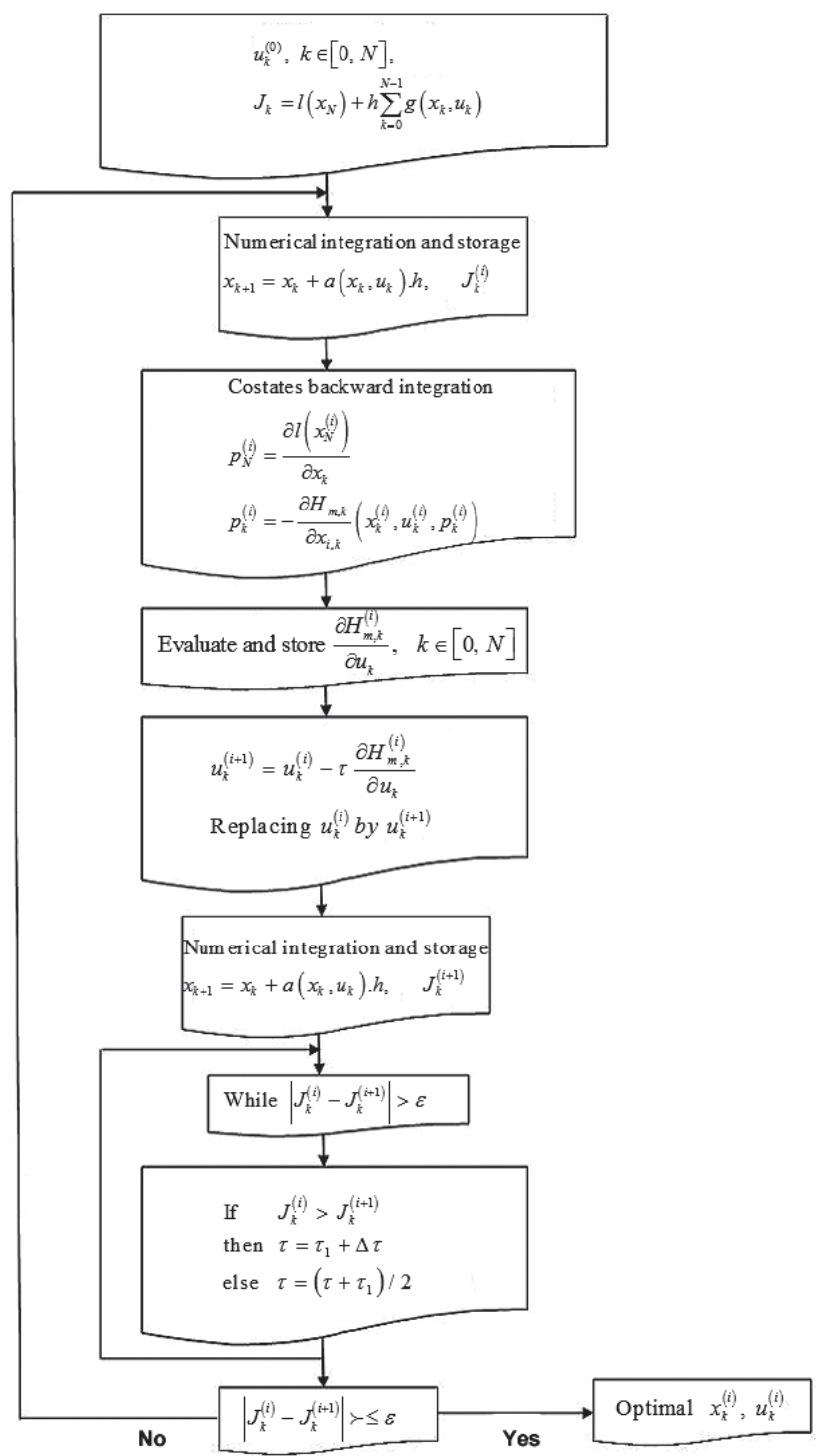

Fig. 4 - Steepest descent gradient flow chart

\section{Gradient Projection algorithm}

The gradient projection algorithm is an iterative numerical procedure for determining an extremum of an objective function of several variables, which should satisfy various linear constraints. ${ }^{18}$ In order to apply the gradient projection optimization algorithm, first let us consider the nonlinear system (4) and then, a cost functional composed of states and input variable is designed (5). The objective is to find an admissible control signal $u^{*}$ which forces the system, with known initial state $x\left(t_{0}\right)=x_{0}$, to track an admissible trajectory $x^{*}$ minimizing the cost functional.

Since the gradient projection is an algorithm for minimizing a function of several variables, we must approximate the optimal control problem to be solved by a discrete-time one. To accomplish this, the state differential equations are approximated by difference equations, and the integral term in the 
cost functional by a summation. Then, equations (4) and (5) are rewritten as

$$
\begin{gathered}
x_{k+1}=x_{k}+f\left(x_{t}, u_{t}\right) T \\
J_{k}=l\left(x_{N}\right)+T \sum_{k=0}^{N-1} g\left(x_{k}, u_{k}\right)
\end{gathered}
$$

where $T$ is the sampling time used for the approximate difference equations. The required calculations by the gradient projection algorithm are

$$
\begin{gathered}
\frac{\partial f}{\partial x_{k}}=\frac{\partial J_{k}\left(u_{k}^{i+1}\right)}{\partial u_{k}} \\
P_{q}=I-N_{q}\left[N_{q}^{T} N_{q}\right]^{-1} N_{q}^{T} \\
z^{i}=\frac{P_{q}\left[-\frac{\partial J_{k}}{\partial u_{k}}\right]}{\left\|P_{q}\left[-\frac{\partial J_{k}}{\partial u_{k}}\right]\right\|} \\
u_{k}^{i+1}=u^{i}+\tau_{m} z^{i} \\
z^{i T}\left[-\frac{\partial J_{k}\left(u_{k}^{i+1}\right)}{\partial u_{k}}\right]
\end{gathered}
$$

The cost functional $J_{k}$ is entirely expressed in terms of the control values. To achieve this, we substitute (10) into (11). The gradient of $J_{k}$ with respect to $u_{k}$ is evaluated on the $(i+1)$ st trajectory. The projection matrix $\boldsymbol{P}_{q}$ at some point $u_{k}^{i}$ is formed by the linearly independent unit normal $\mathbf{n}_{1}, \ldots, \mathbf{n}_{\mathrm{q}}$ vectors which are orthogonal to hyperplanes (linear boundary) of the search region $R$. This equation is important because it indicates the procedure for changing $u_{k}$ along the boundary of $R$ in the direction of the projected gradient. In order to change $u_{k}$ in the direction of the projected gradient, it is necessary to know the maximum step size which can be used without violating any of the constraints. $\mathbf{z}^{i}$ represents the unit vector on the direction of the projected gradient. ${ }^{1}{ }^{1}$ is the most distant point from $u_{k}^{i}$ along the gradient projection for which no constraints are violated. In order to determine whether the maximum step size $\tau_{m}$ should be used, we form the inner product (16); if it is negative, the maximum step is not taken, and interpolation is used to determine the point where the gradient is orthogonal to hyperplanes of $R$.

Theorem 2. Assume that $f$ is a convex function with continuous second partial derivatives in a closed and bounded convex region $R$ of $E^{n}$. Let $u^{*}$ be a boundary point of $R$ which lies on exactly $q$, $1 \leq q<n$, hyperplanes that are assumed to be lin- early independent. $Q$ ' denotes the intersection of these hyperplanes. The point $u^{*}$ is a constrained global minimum of $f$ if, and only if,

$$
P_{q}\left[-\frac{\partial J_{k}\left(u^{*}\right)}{\partial u_{k}}\right]=0
$$

and

$$
\left[N_{q}^{T} N_{q}\right]^{-1} N_{q}^{T}\left[-\frac{\partial J_{k}\left(u^{*}\right)}{\partial u_{k}}\right] \leq 0
$$

Proof of this theorem is given in $\mathrm{Kirk}^{18}$ and a flow chart of this procedure is shown in Figure 5.

\section{Results and discussion}

\section{Steepest Descent application}

The results of the SSF process model obtained with the steepest descendent algorithm subject to the conditions described in Table 1 are presented. Firstly, a cost functional based on the dynamic states and the control input to maximize the $S$. thermophilum microorganisms production is established. The objective is to obtain a selected substrate for edible mushroom cultivation using a weighted control effort, which represents saved energy. Therefore, the following cost functional is proposed:

$$
J=-\int_{t_{0}}^{t_{f}}\left(Q x_{2}^{2}+R_{m} u^{2}\right) \mathrm{d} t,
$$

which indicates a maximization of the $x_{2, k}$ variable with a $u_{k}$ weighted consumption. $Q$ is a positive semidefinite real symmetric matrix, and $R_{m}$ is a positive definite real symmetric matrix. ${ }^{18}$

Based on Theorem 1, it is verified that the cost functional is concave and the states are assumed concave for the state-control permissible values. The simulation horizon for the SSF process is 250 hours, and after 12 iterations, the algorithm convergence is reached maximizing the cost functional. The results of the optimization strategy are displayed in Figure 6.

As can be seen, the input air flow trajectory calculated by the optimization algorithm produces an optimal temperature profile. The achieved maximum $S$. thermophilum microorganisms production is $3.77 \mathrm{~kg} \mathrm{~m}^{-3}$, which is higher than the one obtained at constant air flow (Figure 3). The $S$. thermophilum production increases $25.66 \%$ and the input airflow reaches a maximum value of $2.43 \mathrm{~m}^{3} \mathrm{~h}^{-1}$ at 105 hours. The temperature reaches its maximum value of $50.8{ }^{\circ} \mathrm{C}$ at 73 hours, which is very close to the experimental results (Figure 2). Actinobacteria production is $1.14 \mathrm{~kg} \mathrm{~m}^{-3}, 45 \%$ lower as compared 


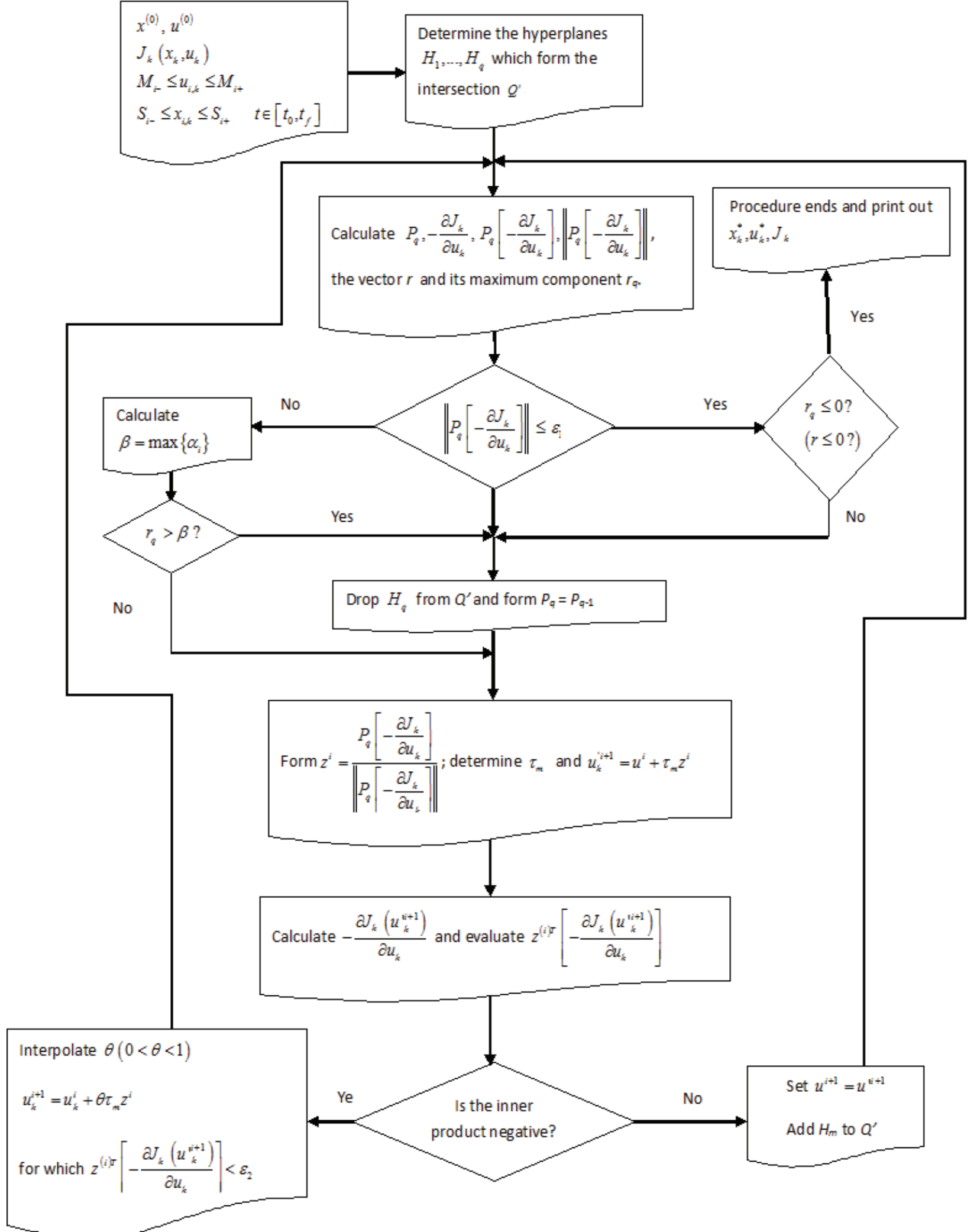

Fig. 5 - Gradient Projection flow chart

with the one at constant air flow. Inhibitor microorganism concentration is $0.23 \mathrm{~kg} \mathrm{~m}^{-3}$, which represents a minimum growth as compared with the $S$. thermophilum ones. The calculated input air flow and the optimal temperature profile maximize
S. thermophilum microorganisms concentration, which is the aim of the process. The convergence for a $u^{(0)}$ variety is a feature of the optimization algorithm; the results at different initial trajectories for $u^{(0)}$ are presented in Figure 7. 

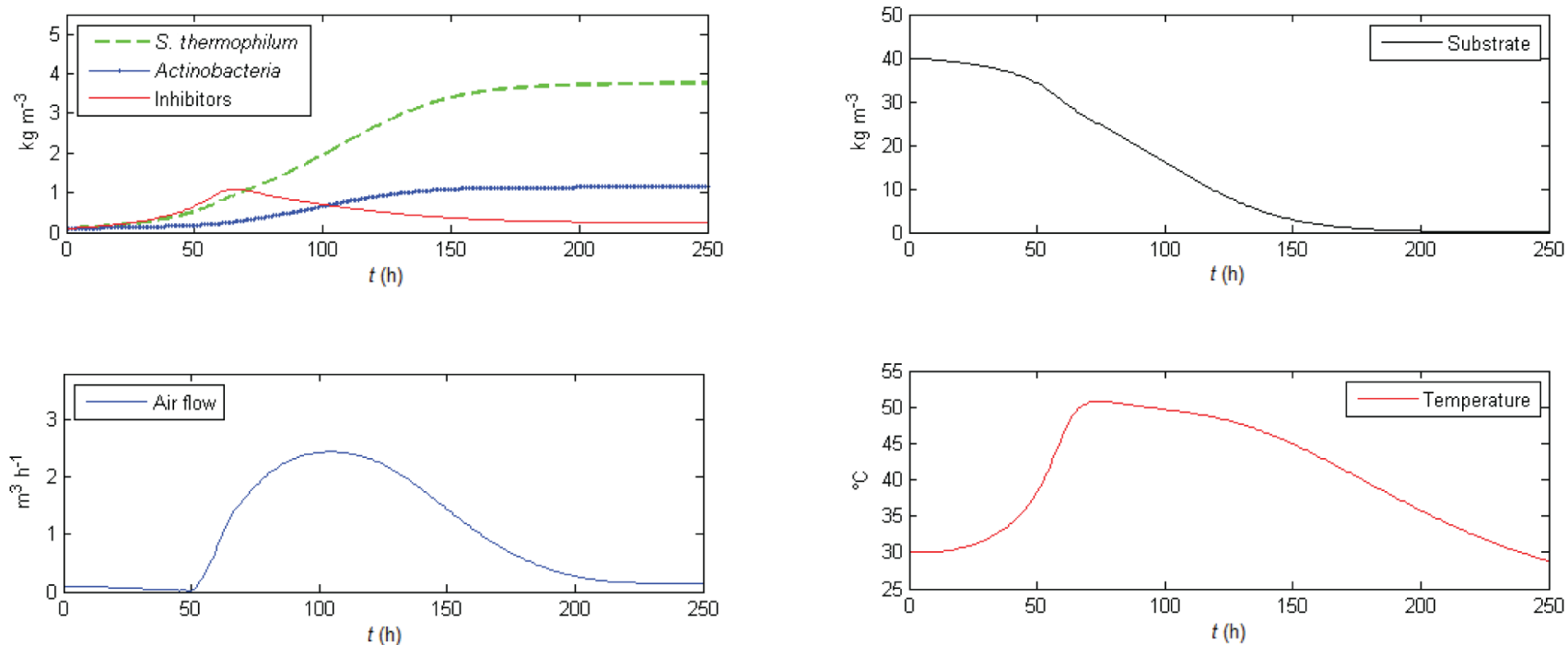

Fig. 6 - SSF model optimal control with $u_{t}^{(0)}=0.1$

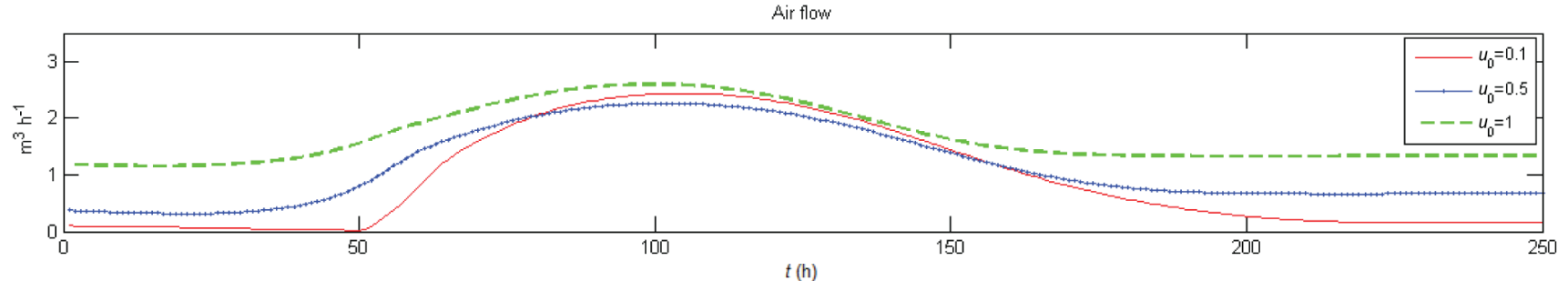

$t(\mathrm{~h})$

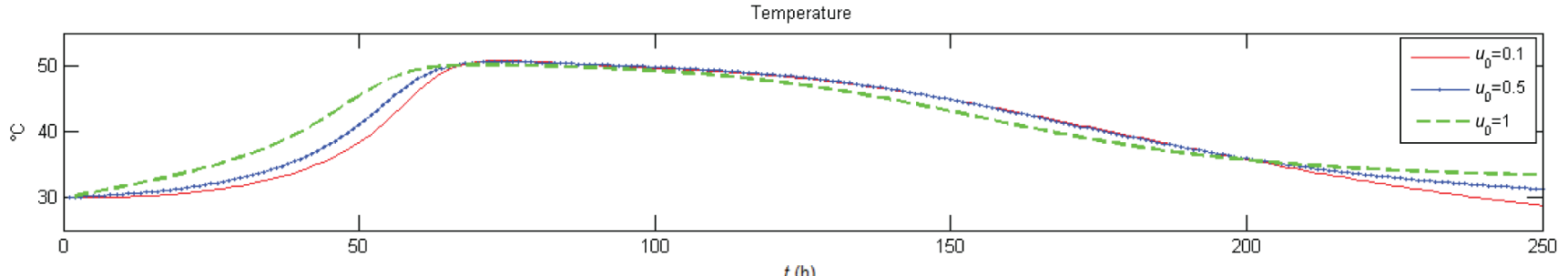

$t$ (h)

S. thermophilum

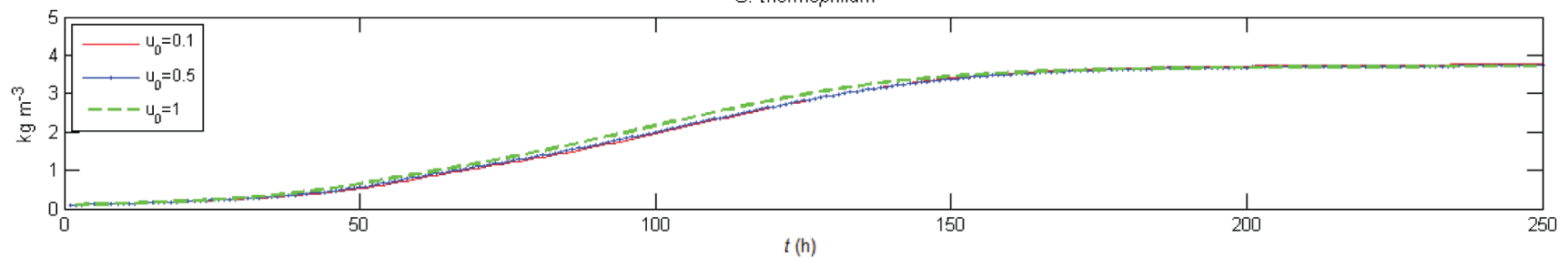

Fig. 7 - FSS model optimal control with $u_{t}^{(0)}$ variety

Figure 7 shows a trajectory comparison for the input air flow, temperature profiles, and $S$. thermophilum microorganism concentration corresponding to different initial control trajectories. As can be seen, algorithm convergence for an initial control trajectory variety is verified. System response in the presence of disturbances, such as temperature variations of the input air flow and different initial conditions of the model can be analyzed. The results via simulation of these scenarios are presented in Figures 8 and 9 .
Figure 8 shows a comparison of the input air flow, process temperature, and $S$. thermophilum concentration for different temperature values of the input air flow $\left(T_{0 \mathrm{a}}\right)$. Algorithm convergence for these results is achieved after 14 iterations. The results show that a decrease in $T_{0 \mathrm{a}}\left(15^{\circ} \mathrm{C}\right)$ produces a $S$. thermophilum concentration increase, reduces the control effort, and an inhibitor concentration increase is obtained. A $T_{0 \mathrm{a}}$ increase produces a control effort increase without a greater production of $S$. thermophilum concentration, and the inhibitor con- 

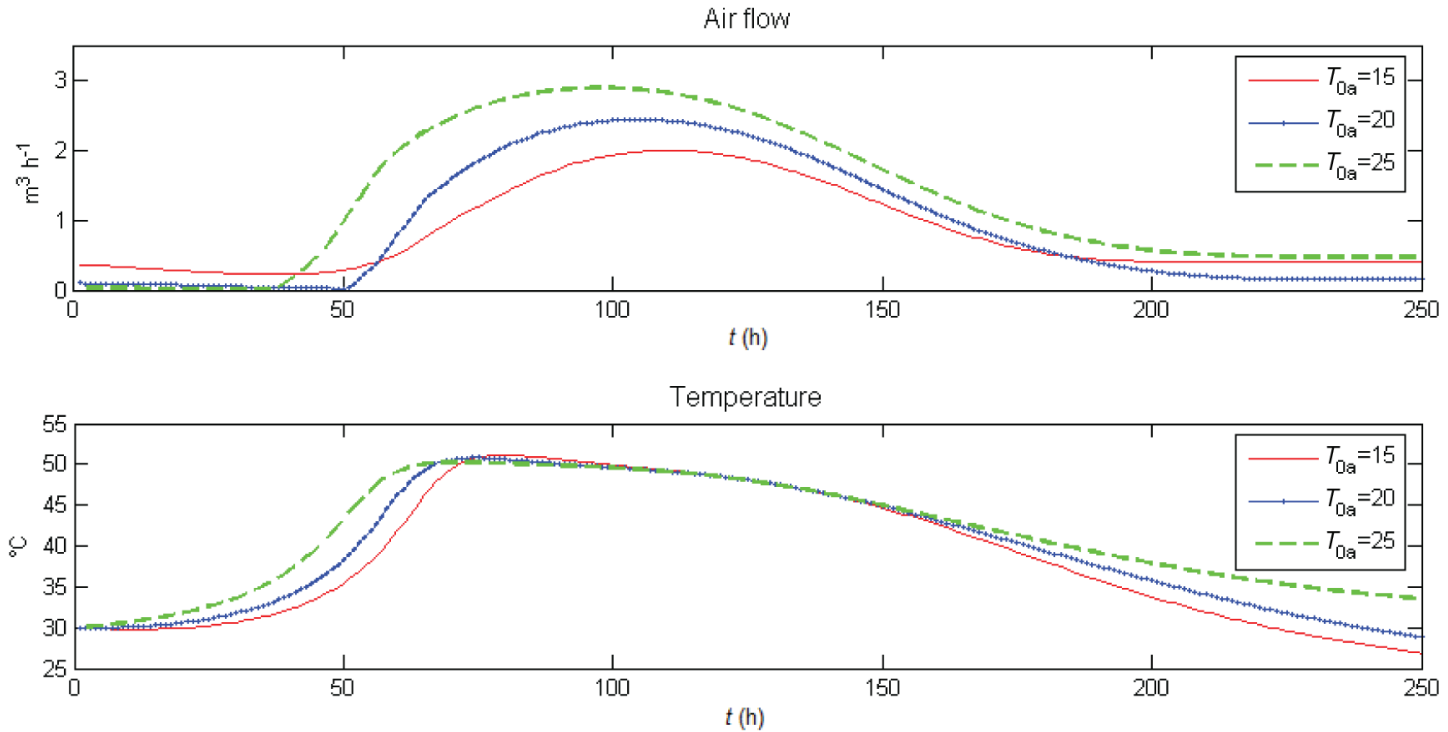

S. thermophilum

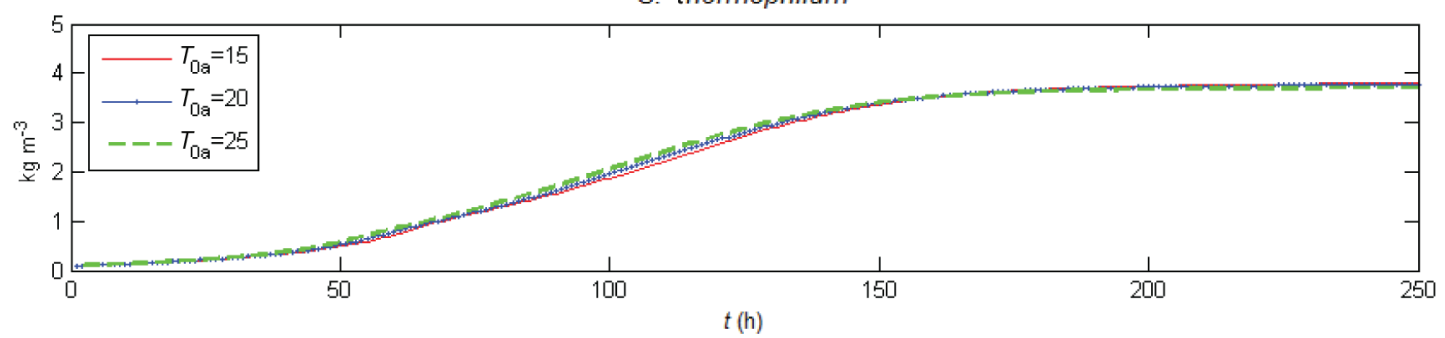

Fig. 8 - SSF model trajectories comparison for temperature disturbance on $u_{t}^{(0)}$

centration is decreased. According to these results, it is concluded that an appropriate temperature selection for the input air flow could improve process performance.

SSF model with an initial condition values increase is tested with the following values: $x_{1,0}=0.2$; $x_{2,0}=0.3 ; x_{3,0}=0.15, x_{4,0}=45, x_{5,0}=0.35, x_{6,0}=35$. Algorithm convergence is achieved after 14 iterations, and the results are displayed in Figure 9.

The initial conditions play an important role in the SSF process; initial concentration of microorganisms affects the reaction rate reaching a higher microorganism concentration. S. thermophilum microorganisms reached a maximum concentration of $x_{2}=4.7 \mathrm{~kg} \mathrm{~m}^{-3}$ with maximum control effort of $u_{\mathrm{t}}=3.22 \mathrm{~m}^{3} \mathrm{~h}^{-1}$ at $60 \mathrm{~h}$. Actinobacteria microorganisms concentration also increased with $x_{1}=2.05$ $\mathrm{kg} \mathrm{m}^{-3}$ and inhibitors decreased with $x_{3}=0.11 \mathrm{~kg} \mathrm{~m}^{-3}$. Microorganism concentrations reach a maximum concentration at the end of the process.

In order to verify the effects of the parameter $\delta_{i}$ on the optimization algorithm, the standard deviation described in Table 2 is considered, and simulations results are displayed in Figure 10.

As can be seen, the sensitive parameter modifies the transient state and the maximum attainable point of the temperature. Considering the nominal $\delta_{i}$ value with positive standard deviation, the temperature state increases to reach $52{ }^{\circ} \mathrm{C}$ where it remains for $40 \mathrm{~h}$. The $S$. thermophilum concentration decreases due to the suboptimal temperature range. On the other hand, considering the nominal $\delta_{i}$ value with the negative standard deviation, the maximum temperature reaches $50{ }^{\circ} \mathrm{C}$ in a short time and then decreases quickly. An S. thermophilum increased concentration is reached due to the optimal temperature range. According to these results, it is concluded that an appropriate $\delta_{i}$ value could improve process performance.

\section{Gradient Projection application}

The results of the SSF process model obtained with the gradient projection algorithm subject to the conditions described in Table 1 are presented. Firstly, the cost functional (19) and SSF model (1) are discretized, and then the methodology used with the previous algorithm is applied. According to convergence requirements, the control trajectory must remain in a concave region and the cost functional should be concave. The cost functional (19) is found concave and each component of $f\left(x_{\mathrm{t}}, u_{\mathrm{t}}\right)$ is assumed concave or convex for admissible state-control trajectories. Then, control linear restrictions are established to search the optimal control trajectory in a 

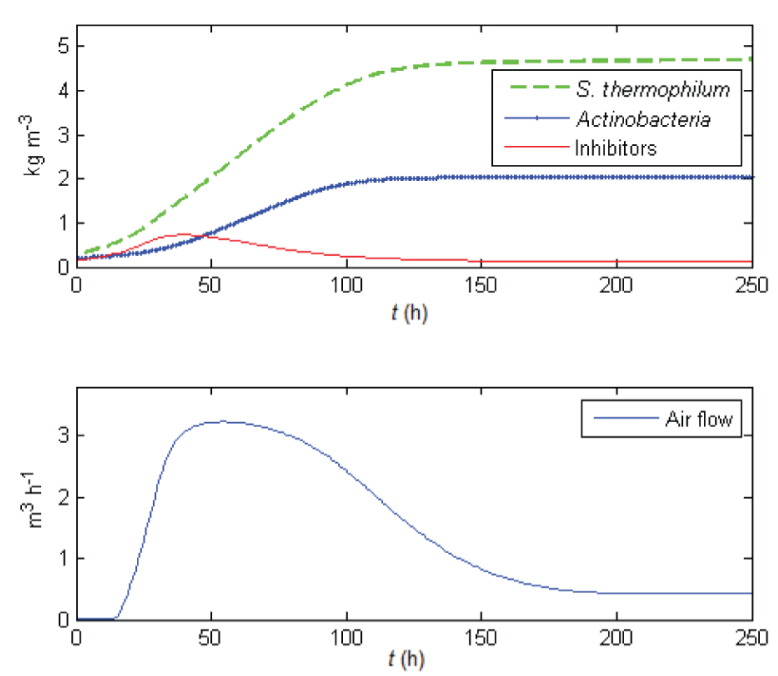
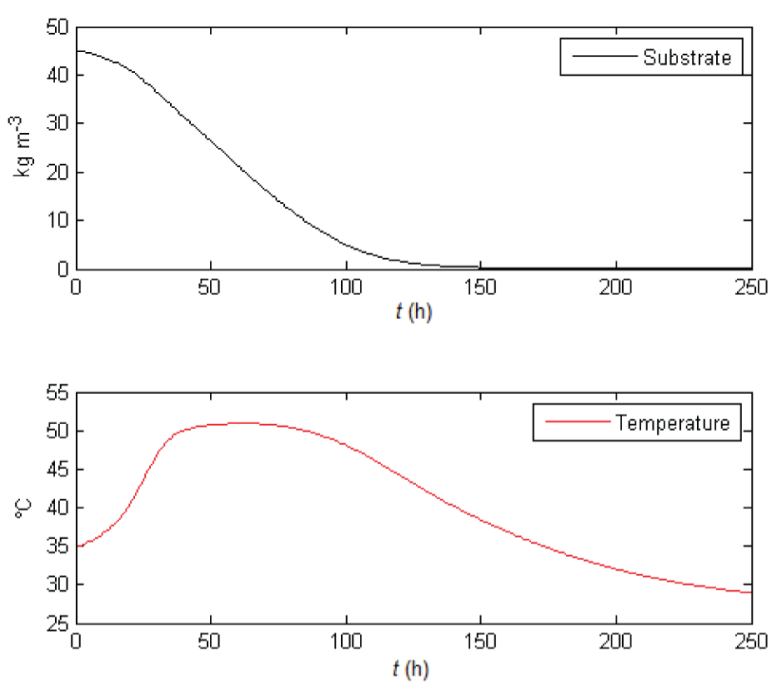

Fig. 9 - SSF model response with initial conditions increase

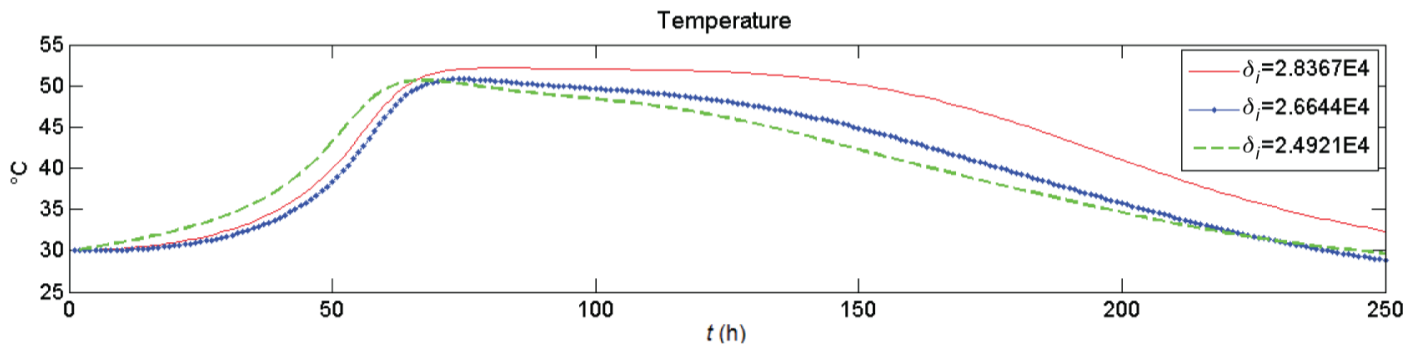

S. thermophilum

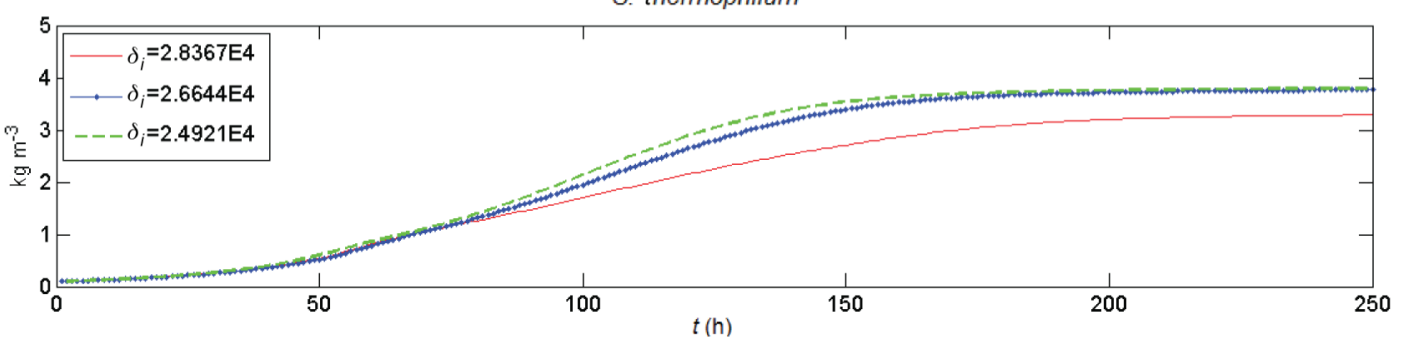

Fig. $10-S S F$ model response with sensitive parameter $\delta_{i}$

bounded and concave region. Previously, on the descending gradient results it had been noticed that the control variable remained in a positive range not greater than $4 \mathrm{~m}^{3} \mathrm{~h}^{-1}$; based on this fact, the following linear restrictions are established

$$
0 \leq u_{k} \leq 4, \quad k=0,1, \ldots, N-1 .
$$

By the proof of convex set, it is clear that the control linear restriction is a convex set. ${ }^{18}$ The simulation horizon for the SSF process is 250 hours, and after 10 iterations, the algorithm convergence is reached maximizing the cost functional. The results of the optimization strategy are displayed in Figure 11.

The calculated input air flow trajectory with this control strategy produces an optimal temperature profile in order to reach a $S$. thermophilum production of $3.753 \mathrm{~kg} \mathrm{~m}^{-3}$. Comparing this result with the one using steepest descent gradient, a higher concentration of $0.47 \%$ is obtained. The input air flow reaches a maximum value of $2.57 \mathrm{~m}^{3} \mathrm{~h}^{-1}$ at 108 hours, and the temperature reaches $50.97{ }^{\circ} \mathrm{C}$ at 75 hours. The Actinobacteria microorganism production is $1.238 \mathrm{~kg} \mathrm{~m}^{-3}$, which is a decrease of $40.85 \%$ compared to achieved production at constant air flow. Inhibitor microorganism growth is $0.21 \mathrm{~kg} \mathrm{~m}^{-3}$, which represents a minimum growth compared with $S$. thermophilum ones. The results of this control optimization method are very similar to the steepest descent ones, emphasizing a smaller iteration number to optimize the SSF process. Algorithm convergence occurs for a variety of initial trajectories $\left(u^{(0)}\right)$, as presented in Figure 12.

Figure 12 shows a comparison of the input air flow trajectories, temperature profiles and $S$. thermophilum microorganisms concentration, for differ- 

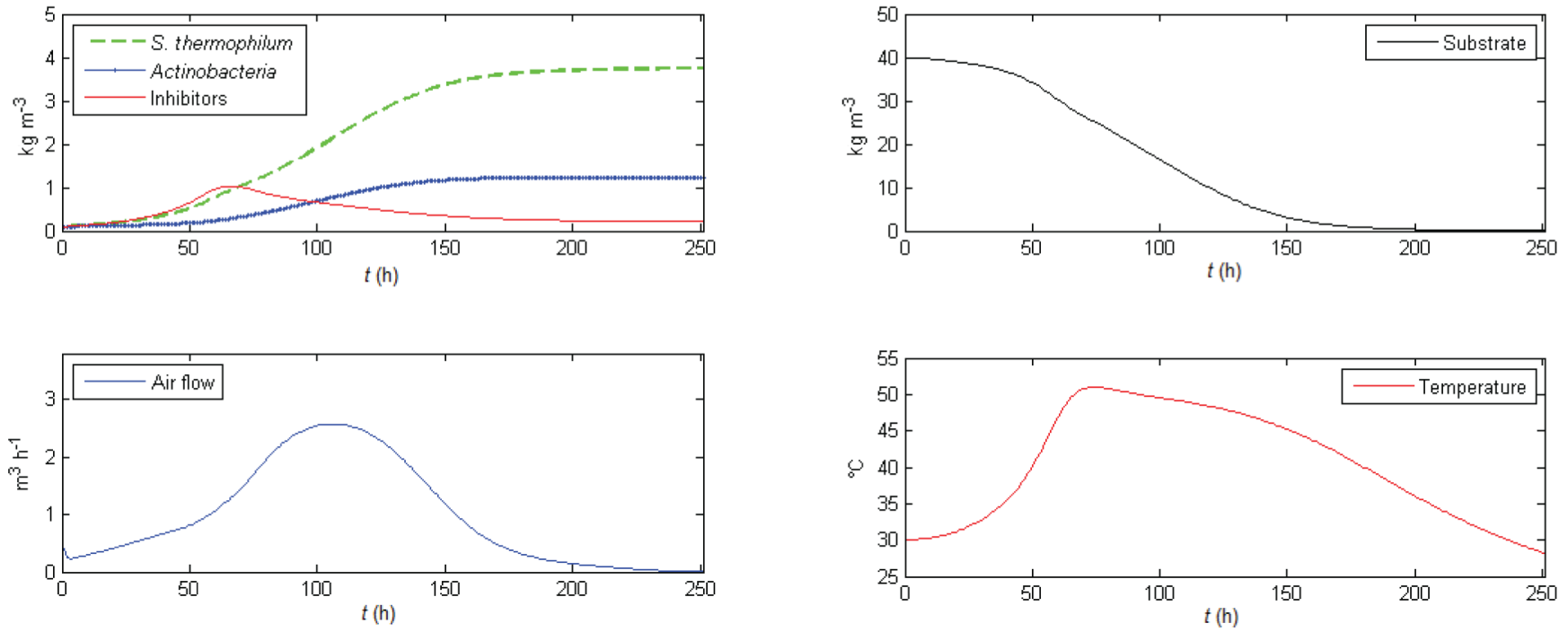

Fig. 11 - SSF model optimal control with $u_{k}^{(0)}=0.1$

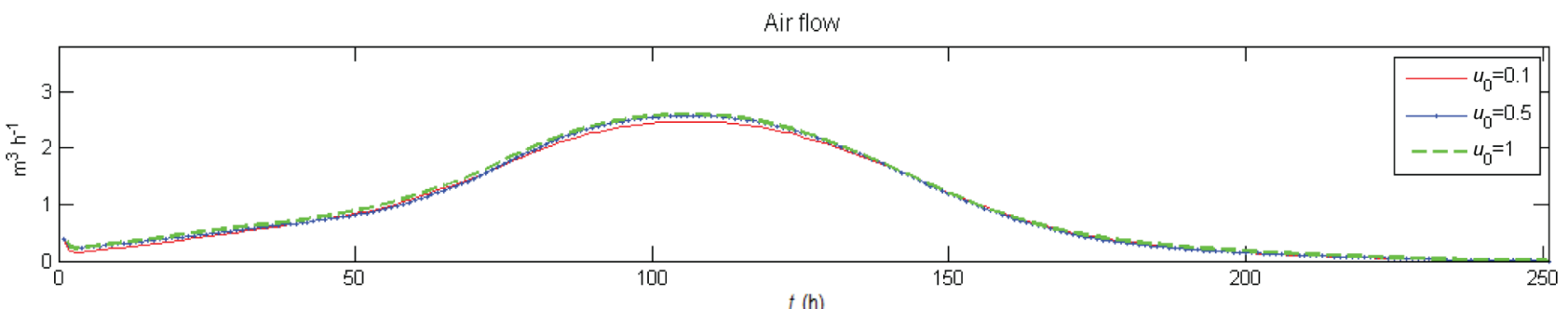

Temperature

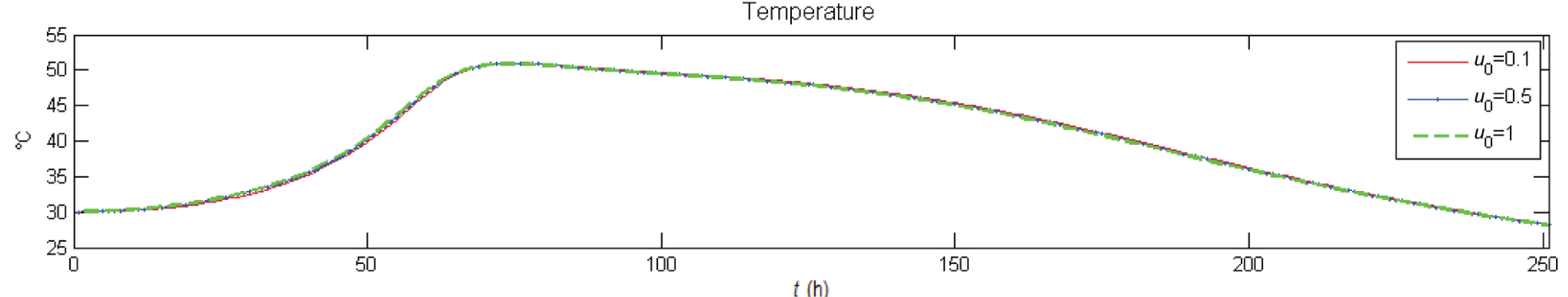

S. thermophilum

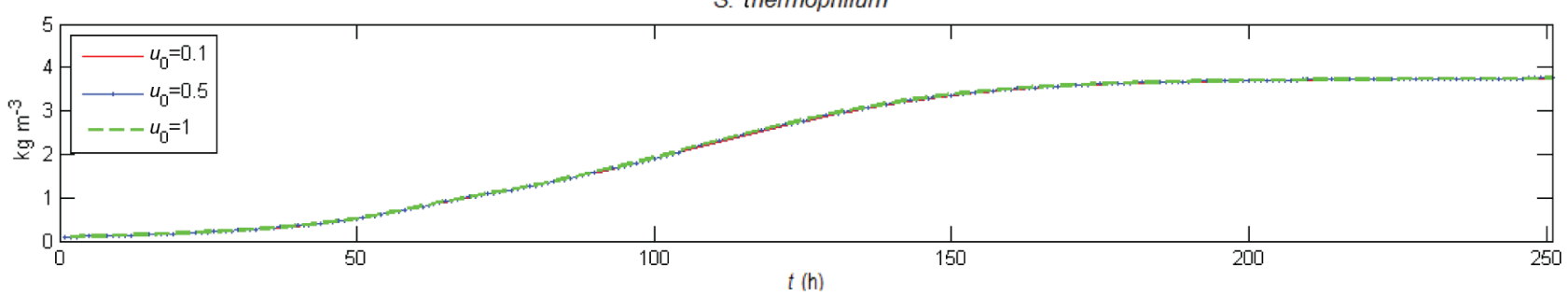

Fig. 12 - SSF model optimal control with $u_{k}^{(0)}$ variety

ent initial control trajectories. As can be seen algorithm convergence for an initial control trajectory variety is verified. Thus, system response in the presence of disturbances, such as temperature variations of the input air flow and different initial conditions of the model can be analyzed. The results via simulation of these scenarios are presented in Figures 13 and 14.

Figure 13 shows a comparison of the input air flow, process temperature and $S$. thermophilum con- centration for different temperature values of the input air flow $\left(T_{0 \mathrm{a}}\right)$. Algorithm convergence for these results is achieved after 14 iterations. As in the previous test with the steepest descent gradient algorithm, the results show that a decrease in $T_{0 \mathrm{a}}$ $\left(15{ }^{\circ} \mathrm{C}\right)$ produces a $S$. thermophilum concentration increase, reduces the control effort, and an inhibitor concentration increase is obtained. A $T_{0 \mathrm{a}}$ increase produces a control effort increase without a greater production of $S$. thermophilum concentration, and 
the inhibitor concentration is decreased. According to these results, it is concluded that an appropriate temperature selection for the input air flow could improve process performance.

The control strategy is evaluated with an initial condition values increase as the one used with steepest descent gradient algorithm. Algorithm convergence is achieved after 14 iterations, and the results are displayed in Figure 14.

As in previous results for the steepest descent algorithm, an increase in microorganisms concen- tration produces a higher microorganism concentration. Figure 14 indicates that the $S$. thermophilum microorganisms achieve a $4.7 \mathrm{~kg} \mathrm{~m}^{-3}$ production with a maximum control effort of $3.22 \mathrm{~m}^{3} \mathrm{~h}^{-1}$ at $55 \mathrm{~h}$. The Actinobacteria concentration achieves a maximum of $2.05 \mathrm{~kg} \mathrm{~m}^{-3}$ and the inhibitor concentration is decreased achieving $0.11 \mathrm{~kg} \mathrm{~m}^{-3}$.

As above, in order to verify the effects of parameter $\delta_{i}$ on the optimization algorithm, the standard deviation described in Table 2 is considered, and simulations results are displayed in Figure 15.
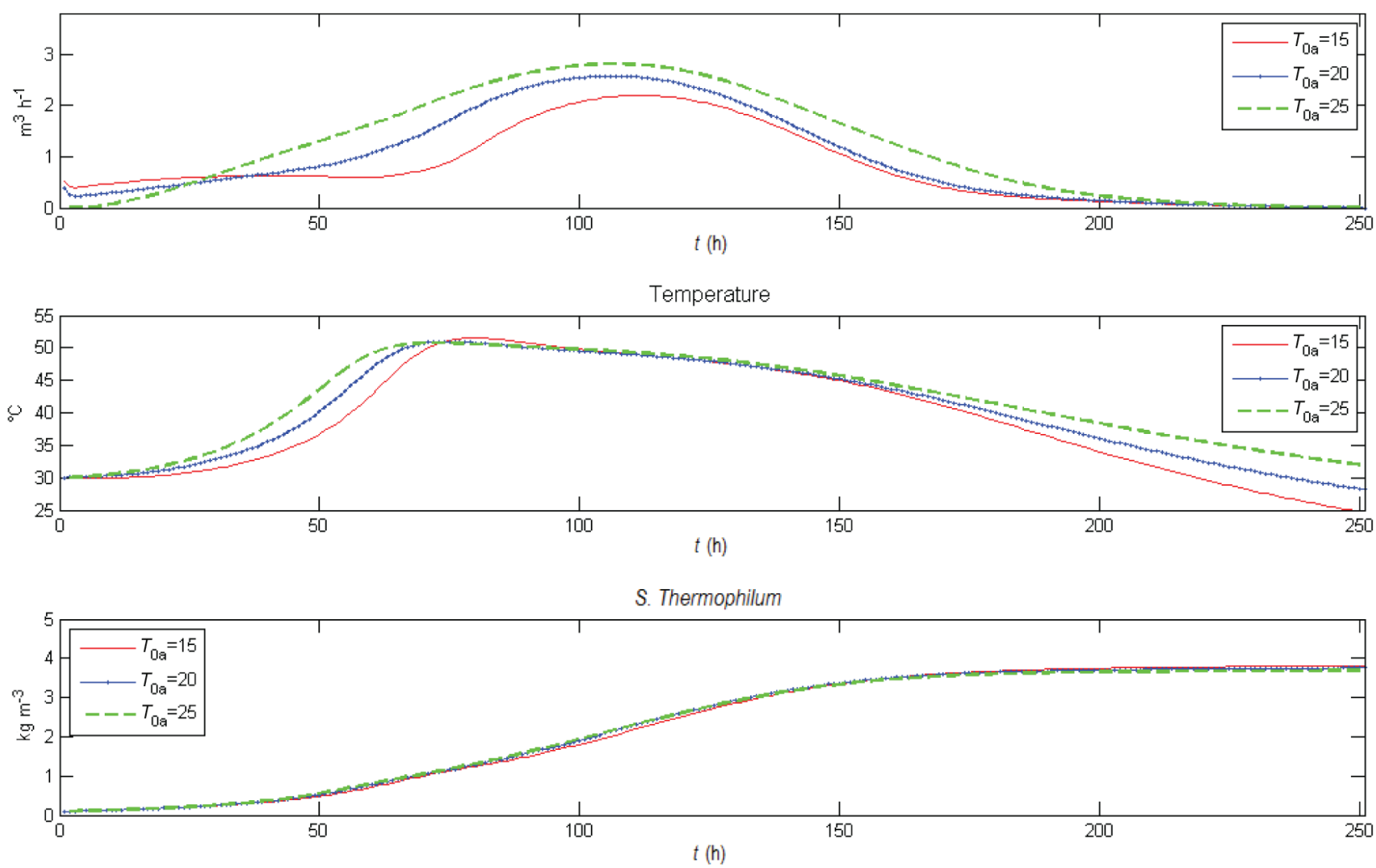

Fig. 13 - SSF model trajectories comparison for temperature disturbance on $u_{k}^{(0)}$
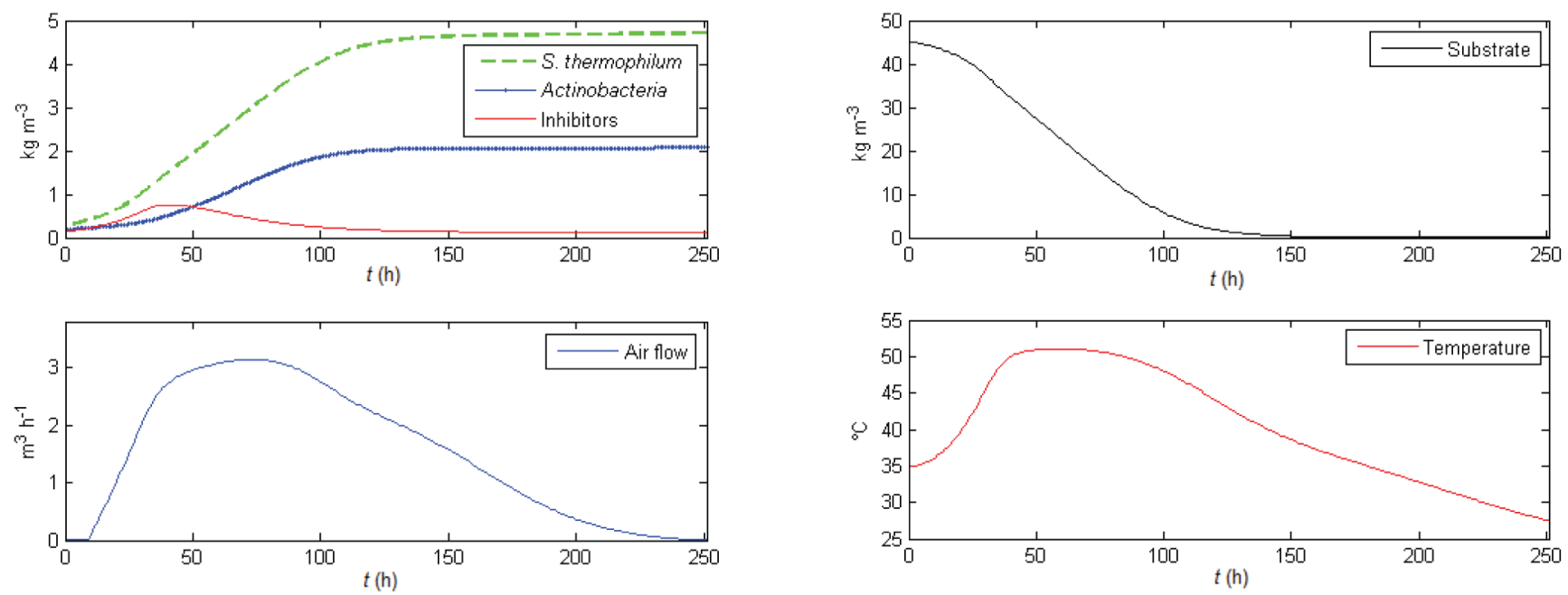

Fig. 14 - SSF model response with initial conditions increase 


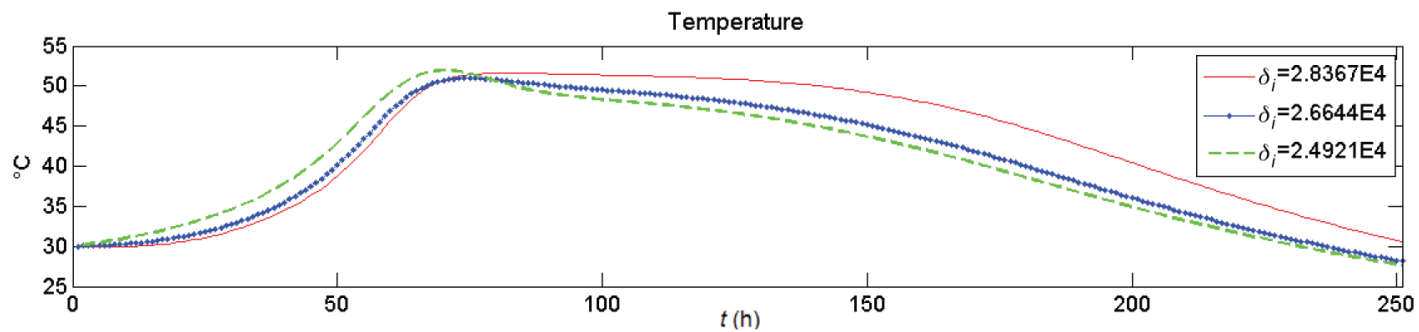

S. thermophilum

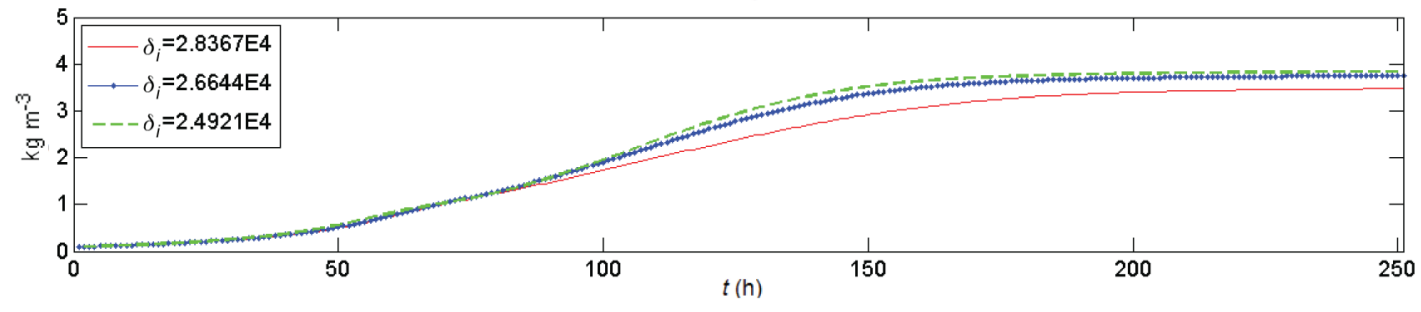

Fig. 15 - SSF model response with sensitive parameter $\delta_{i}$

In this case, the gradient projection algorithm presents a variation in the transient state and the maximum attainable point of the temperature as compared with the previous algorithm. Considering the nominal $\delta_{i}$ value with positive standard deviation, temperature state increases to reach $51.6{ }^{\circ} \mathrm{C}$ where it remains for $10 \mathrm{~h}$. The $S$. thermophilum concentration presents a minor decrease due to suboptimal temperature range. On the other hand, considering the nominal $\delta_{i}$ value with the negative standard deviation, the maximum temperature reached is $51.9^{\circ} \mathrm{C}$ in a short time, and then decreases quickly. A $S$. thermophilum increased concentration is reached due to optimal temperature range. According to these results, it is concluded that an appropriate $\delta_{i}$ value could improve process performance.

\section{Conclusions}

In this paper, optimal control strategies to determine temperature profiles, for a solid substrate fermentation reactor of selective substrate production have been developed and compared. The nonlinear model includes dynamics of three different microorganisms types, heat transfer, mass transfer with microbial reaction, input air balance and dynamic internal temperature. System stability is verified via simulation in open loop. The predicted reactor temperature behavior has been previously validated experimentally. The steepest decent gradient and gradient projection optimization algorithms are used to determine the dynamic input aeration rate of the system in order to control the temperature, which stimulates microorganisms growth to obtain a selective substrate for edible mushroom cultivation. The optimization algorithms optimize a concave cost functional, which is related to the fu- ture behavior of the system, which depends on the control trajectories calculated in the defined time interval. The proposed optimization strategies calculated an optimum input air flow trajectory in the presence of disturbances that maximize the desired $S$. thermophilum microorganism production with a weighted control effort. The steepest descent calculates an input air flow trajectory that allows a $25.66 \%$ higher production than the process with a constant air flow. The gradient projection algorithm calculates a similar input air flow trajectory that allows a $25.06 \%$ higher production than that obtained at constant air flow. It is concluded that the optimization strategies determine optimal trajectories in the presence of disturbances. The advantages of the applied algorithms are that they can work with highly nonlinear systems, convergence occurs for a variety of initial conditions, and few iterations are required. As future work, optimal control trajectories will be implemented in a real-time process.

\section{Abbreviations and symbols}

$x \quad$ - dynamic states

$x_{0} \quad$ - initial state

$x_{1} \quad$ actinobacteria, $\mathrm{kg} \mathrm{m}^{-3}$

$x_{2}-$ Scytalidium thermophilum, $\mathrm{kg} \mathrm{m}^{-3}$

$x_{3}$ - inhibitors, $\mathrm{kg} \mathrm{m}^{-3}$

$x_{4}$ - substrate, $\mathrm{kg} \mathrm{m}^{-3}$

$x_{5}$ - oxygen, $\mathrm{kg} \mathrm{m}^{-3}$

$x_{6}-$ temperature, ${ }^{\circ} \mathrm{C}$

$\mu \quad-$ microbial growth specific rate, $\mathrm{h}^{-1}$

$\lambda \quad-$ mortality specific rate, $\mathrm{h}^{-1}$

$\gamma_{i}-$ substrate yield coefficient

$\phi_{i} \quad$ - oxygen consumption coefficient 
$V \quad$ - volume of the reactor, $\mathrm{m}^{3}$

$u \quad-$ input fresh air flow, $\mathrm{m}^{3} \mathrm{~h}^{-1}$

$\varphi \quad-$ constant which relates the solid and humid contained of the substrate

$\psi \quad-$ heat transfer constant to the outside, $\mathrm{kJ} \mathrm{m}^{-3} \mathrm{~h}^{-1}{ }^{\circ} \mathrm{C}^{-1}$

$\delta \quad-$ heat generation coefficient, $\mathrm{kJ} \mathrm{kg}^{-1}$

$\zeta-$ coefficient that relates the air density and the reactor volume, $\mathrm{kg}$

$\pi \quad-$ function that depends on the saturation enthalpy, $\mathrm{kJ} \mathrm{kg}^{-1}$

$\pi_{f} \quad-$ function that depends on the damp heat, $\mathrm{kJ} \mathrm{kg}^{-1}$

$J-$ cost functional

$H_{m}-$ Hamiltonian

$p_{t}-$ costates

$t$ - time, h

$t_{0} \quad-$ initial time, $\mathrm{h}$

$t_{f} \quad-$ final time, $\mathrm{h}$

$k$ - discrete time, $\mathrm{h}$

$T$ - sampling time, $\mathrm{h}$

$P_{q}-$ projection matrix

$N_{q}$ - hyperplanes

$Q^{\prime}$ - intersection of hyperplanes

$\mathrm{z}^{\mathrm{i}} \quad-$ unit vector on the direction of the projected gradient

$\tau_{m}-$ maximum step size

$R \quad-$ real space

$E^{n}-$ Euclidean space

$R_{m} \quad$ - positive definite real symmetric matrix

$Q \quad$ - positive semidefinite real symmetric matrix

\section{References}

1. Bhargav, S., Panda, B. P., Ali, M., Javed, S., Solid-state fermentation: An overview, Chem. Biochem. Eng. Q. 22 (2008) 49

2. Thomas, L., Larroche, C., Pandey, A., Current developments in solid-state fermentation, Biochem. Eng. J. 81 (2013) 146.

doi: https://doi.org/10.1016/j.bej.2013.10.013

3. Arce-Cervantes, O., Saucedo-García, M., Lara, H. L., Ramírez-Carrillo, R., Cruz-Sosa, F., Loera, O., Alternative supplements for Agaricus bisporus production and the response on lignocellulolytic enzymes, Sci. Hortic. 192 (2015) 375.

doi: https://doi.org/10.1016/j.scienta.2015.06.030

4. Savoie, J. M., Mata, G., Chapter 5 - Growing Agaricus bisporus as a Contribution to Sustainable Agricultural Development, Mushroom Biotechnology, Academic Press, San Diego, 2016, pp 69-91.

5. Lin, Y., Ge, X., Li, Y., Solid-state anaerobic co-digestion of spent mushroom substrate with yard trimmings and wheat straw for biogas production, Bioresource Technol. 169 (2014) 468 . doi: https://doi.org/10.1016/j.biortech.2014.07.020

6. Reis, F. S., Barros, L., Martins, A., Ferreira, I. C., Chemical composition and nutritional value of the most widely appreciated cultivated mushrooms: an inter-species comparative study, Food Chem. Toxicol. 50 (2012) 191. doi: https://doi.org/10.1016/j.fct.2011.10.056

7. Miles, P. G., Chang, S. T., Mushrooms: cultivation, nutritional value, medicinal effect, and environmental impact, CRC press, New York, 2004, pp 221-235.

8. Straatsma, G., Gerrits, J. P., Thissen, J. T., Amsing, J. G., Loeffen, H., Van Griensven, L. J., Adjustment of the composting process for mushroom cultivation based on initial substrate composition, Bioresource Technol. 72 (2000) 67. doi: https://doi.org/10.1016/S0960-8524(99)00088-7

9. Coello-Castillo, M. M., Sánchez, J. E., Royse, D. J., Production of Agaricus bisporus on substrates pre-colonized by Scytalidium thermophilum and supplemented at casing with protein-rich supplements, Bioresource Technol. 100 (2009) 4488.

doi: https://doi.org/10.1016/j.biortech.2008.10.061

10. Gonzalez-Figueredo, C., de La Torre, L. M., Sanchez, A., Dynamic Modelling and Experimental Validation of a Solid State Fermentation Reactor, IFAC Proceedings Volumes, 43 (2010) 221.

11. Mitchell, D. A., Berovič, M., Krieger, N., Solid-state fermentation bioreactors: fundamentals of design and operation, Springer Berlin, Heidelberg, 2006, pp 295-362. doi: https://doi.org/10.1007/3-540-31286-2 22

12. Raghavarao, K. S. M. S., Ranganathan, T. V., Karanth, N. $G$., Some engineering aspects of solid-state fermentation, Biochem. Eng. J. 13 (2003) 127.

doi: https://doi.org/10.1016/S1369-703X(02)00125-0

13. von Meien, O. F., Luz Jr, L. F., Mitchell, D. A., Perez-Correa, J. R., Agosin, E., Fernández-Fernández, M., Arcas, J. $A$., Control strategies for intermittently mixed, forcefully aerated solid-state fermentation bioreactors based on the analysis of a distributed parameter model, Chem. Eng. Sci. 59 (2004) 4493 doi: https://doi.org/10.1016/j.ces.2004.06.027

14. Chen, H. Z., Xu, J., Li, Z. H., Temperature control at different bed depths in a novel solid-state fermentation system with two dynamic changes of air, Biochem. Eng. J. 23 (2005) 117 doi: https://doi.org/10.1016/j.bej.2004.11.003

15. González-Figueredo, C., Ayala, O. R., Aguilar, S., Aroche, O., Loukianov, A., Sanchez, A., Optimal temperature tracking of a solid state fermentation reactor, Comput. Aided Chem. Eng. 29 (2011) 839. doi: https://doi.org/10.1016/B978-0-444-53711-9.50168-1

16. Sánchez, A., Loukianov, A. G., Aroche, O., Continuous Sliding Mode Temperature Tracking of a Solid State Fermentation Reactor for Substrate Production, IFAC Proceedings Volumes, 46 (2013) 18

17. Wiegant, W. M., Growth characteristics of the thermophilic fungus Scytalidium thermophilum in relation to production of mushroom compost, Appl. Environ. Microb. 58 (1992) 1301.

18. Kirk, D. E., Optimal control theory: an introduction, Courier Corporation, New York, 2012, pp 329-409. 